\section{Commentary: Fortunately enough, most human beings are not rats}

\author{
Jean Bachet, MD, FEBCTS
}

The short study by Lee and colleagues ${ }^{1}$ titled "Persistent Cognitive, Neurogenic, and Neuroinflammatory Effects in a Rat Model of Cardiopulmonary Bypass," which appears in the current issue of the Journal, tends to demonstrate the negative effect of cardiopulmonary bypass (CPB) in terms of cognitive function in rats and, obviously, by extension in human beings. ${ }^{1}$ This study is quite interesting and could shed some light on a problem that remains not clearly explained.

The methodology used by Lee and colleagues ${ }^{1}$ seems totally appropriate. The CPB technique has been carried out in a proper manner, with the usual cannulation sites and modes, adequate flow and temperature, and so on. The animals were adequately trained and managed after training, and the tests carried out 6 months after the initial experiment were obviously demonstrative.

As a cardiovascular surgeon, my knowledge in neuroanatomy and neurophysiology is too limited to allow me to assess, objectively and in a relevant manner, the results of the anatomic and histologic analysis of the animals' brains. Considering the quality of the whole experiment, however, we certainly must accept those results as convincing.

So, the conclusion of this commentary therefore would seem to be that we totally agree with Lee and colleagues, ${ }^{1}$ that their experimental results are unquestionable, and that CPB is definitely harmful. Is this so? Indeed, as many studies carried out in animals and extended to human beings, the current study raises some questions.

First, one may observe that the number of animals included is quite limited (6 in each group). For

\footnotetext{
From the Association Pour le Développement et l'Amélioration des Techniques de Dépistage et de Traitement des Maladies Cardio-vasculaires (ADETEC), Suresnes, France.

Disclosures: Author has nothing to disclose with regard to commercial support.

Received for publication Jan 2, 2020; accepted for publication Jan 4, 2020; available ahead of print Jan 25, 2020.

Address for reprints: Jean Bachet, MD, FEBCTS, Association Pour le Développement et l'Amélioration des Techniques de Dépistage et de Traitement des Maladies Cardio-vasculaires (ADETEC), 1 Place Marcel Legras, 92150 Suresnes, France (E-mail: jean.bachet@yahoo.fr).

J Thorac Cardiovasc Surg 2020;160:e189-90

$0022-5223 / \$ 36.00$

Copyright (C) 2020 by The American Association for Thoracic Surgery

https://doi.org/10.1016/j.jtcvs.2020.01.017
}

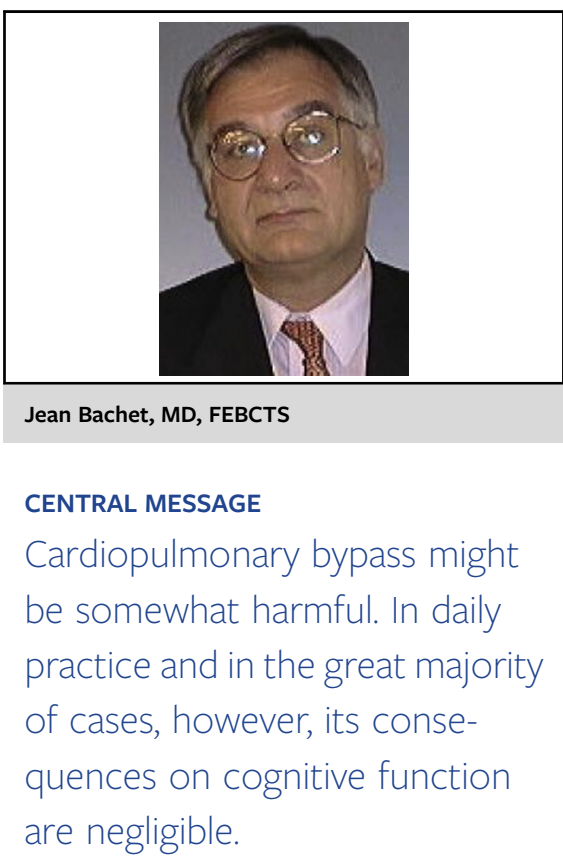

understandable reasons, the use of much larger groups of animals may be difficult and unrealistic. Nevertheless, one cannot help wondering how such a limited number can represent what happens in several millions of patients undergoing $\mathrm{CPB}$ each year and worldwide.

Second, the choice in the reported study of the remembrance of the food place by the rats as their only cognitive activity seems somewhat poorly representative of the range of cognitive activity in human beings. Fortunately enough, human cognitive activity extends across a very large spectrum of anatomic, psychologic, intellectual, affective, learning, creative domains, and so many others features that shape our personal and social life and that have been the major causes of humanity's evolution.

Another matter of concern is indicated in the introduction of the report of Lee and colleagues ${ }^{1}$ by the sentence beginning "Although postoperative cognitive dysfunction is common after CPB." May I disagree? After several decades of active cardiovascular surgery, may I state that the large majority of the patients who underwent a noncomplicated cardiac procedure with $\mathrm{CPB}$ had a complete postoperative maintenance of their cognitive activities and that the proportion of the patients who had problem in this matter is rather reduced, except among very old or severely ill patients. Most patients resume their usual personal and social life. In the clinical setting, impairment of the cognitive activities is mostly observed after difficult cases, including very long procedures with correspondingly long CPB times, cases with important variations in the temperature and the flow, cases with significant blood loss, and, even though 
this is poorly acknowledged, those with a poor quality of venting of the cardiac cavities.

And last, but not least, even if we do admit that CPB is not harmless, we are also obliged to admit that it is still indispensable and mandatory for the most part in cardiac surgery. In the last 2 or 3 decades, many interesting interventional techniques, such as off-pump coronary surgery, transcatheter aortic valve implantation, stent grafting of the aorta, and so on, have been developed that allow the repair of many diseases and troubles without the aid of CPB. They certainly will progress and most probably reduce the need for $\mathrm{CPB}$ in the future. Until that time, however, CPB, adequately carried out, will remain indispensable and at the core of cardiac surgery.

\section{Reference}

1. Wang Y, Tache-Leon C, Machizawa MG, Lisle T, Williams C, Clarke RH, et al Persistent cognitive deficits and neuroinflammation in a rat model of cardiopulmonary bypass. J Thorac Cardiovasc Surg. 2020;160:e185-8.
See Article page e185.

\section{Commentary: Neurocognitive dysfunction after cardiopulmonary bypass: Multiple modalities to rescue the microglia}

\author{
John G. Augoustides, MD, FASE, FAHA
}

Because neurocognitive dysfunction after cardiac surgery remains clinically relevant, therapeutic targets for cognitive rescue are essential. ${ }^{1,2}$ The microglia function as resident macrophages for immune defense throughout the brain. ${ }^{3}$ Activated microglia participate in an inflammatory cascade implicated in cognitive injury after cardiac surgery., Furthermore, rodent models have suggested that impaired neurogenesis may also contribute to this pathogenesis. ${ }^{4,5}$

The study by Wang and colleagues ${ }^{6}$ in this issue of the Journal highlights the central role of inflammation in this setting. In a rat model of cardiopulmonary bypass, the investigators demonstrated that persistent microglial inflammation correlated with neurocognitive dysfunction. Detailed histology also revealed decreased neurogenesis in the hippocampus. ${ }^{6}$ These findings suggest that central

\footnotetext{
From the Cardiovascular and Thoracic Section, Department of Anesthesiology and Critical Care, Perelman School of Medicine, University of Pennsylvania, Philadelphia, Pa.

Disclosures: Author has nothing to disclose with regard to commercial support.

Received for publication Jan 1, 2020; revisions received Jan 1, 2020; accepted for publication Jan 2, 2020; available ahead of print Jan 22, 2020.

Address for reprints: John G. Augoustides, MD, FASE, FAHA, Cardiovascular and Thoracic Section, Department of Anesthesiology and Critical Care, Dulles 680, HUP, 3400 Spruce St, Philadelphia, PA 19104-4283 (E-mail: yiandoc@hotmail. com).

J Thorac Cardiovasc Surg 2020;160:e190-1

$0022-5223 / \$ 36.00$

Copyright (c) 2020 by The American Association for Thoracic Surgery

https://doi.org/10.1016/j.jtcvs.2020.01.005
}

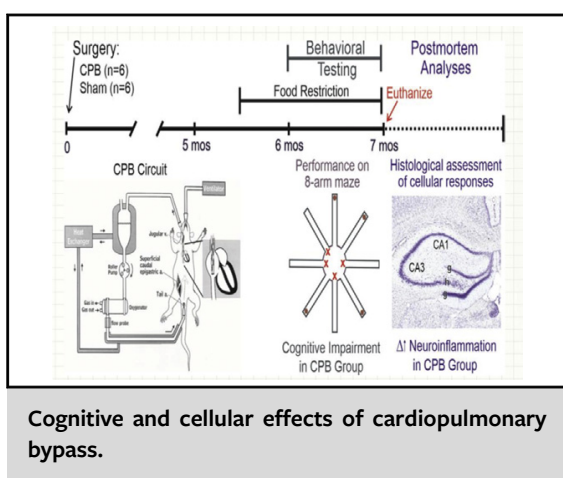

CENTRAL MESSAGE

The microglia offer multiple

therapeutic targets for neurocognitive rescue after cardiac surgery. Future trials should explore multimodal interventions, including modulation of

inflammation inflammation.

and disrupted neurogenesis are likely mechanisms in cognitive injury from cardiopulmonary bypass. ${ }^{4-6}$

How might these observations guide further progress in cognitive rescue for our patients? Avoiding cardiopulmonary bypass in coronary artery bypass grafting has not abolished cognitive injury, despite anaortic techniques and ancillary carbon dioxide. ${ }^{7}$ Further trials will likely refine the conduct of off-pump techniques to reduce the cognitive risk, especially in high-risk groups such as the elderly and frail. 1,2,7,8

What are our options when cardiopulmonary bypass cannot be avoided ${ }^{1,2}$ In deep hypothermic circulatory arrest, recent results from rat knockout models have identified cold-inducible RNA-binding proteins as a microglial 